\title{
Influência de auxina na aclimatização de Oncidium baueri (Orchidaceae)
}

\section{Influence of auxin on acclimatization of Oncidium baueri (Orchidaceae)}

\author{
Mauren Sorace ${ }^{1}$; Ricardo Tadeu Faria ${ }^{2 *}$; Lilian Yukari Yamamoto ${ }^{3}$; \\ Jenniffer A. Schnitzer ${ }^{4}$; Lúcia Sadayo Assari Takahashi ${ }^{5}$
}

Resumo

O presente trabalho teve como objetivo avaliar o enraizamento e desenvolvimento vegetativo de plântulas de Oncidium baueri (Orchidaceae) utilizando o ácido naftaleno acético (ANA), durante a fase de aclimatização. O experimento foi conduzido no período de março à outubro de 2005, no Departamento de Agronomia da Universidade Estadual de Londrina (PR). As plântulas foram obtidas a partir de sementes germinadas in vitro, em meio de cultura (MS). Foram retiradas dos frascos e lavados em água corrente para a remoção do meio de cultura, e em seguida transplantadas em bandejas, com esfagno, e colocados em bancadas suspensas em Casa de Vegetação ( $50 \%$ de retenção da radiação solar). A auxina foi utilizada através de dois modos, imersão rápida das plantas, por 10s (T2, T3, T4), ou quatro pulverizações semanais do substrato (T5, T6, T7). Os tratamentos com ácido naftaleno acético (ANA) foram: T1 - $0 \mathrm{mg} . \mathrm{L}^{-1} ; \mathrm{T} 2$ -

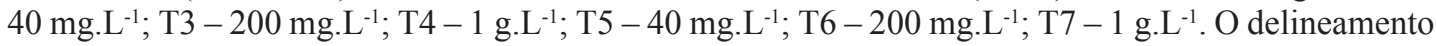
experimental foi inteiramente casualizado com sete tratamentos e três repetições, contendo dez plântulas por parcela. As plantas de Oncidium baueri foram retiradas do substrato e realizados as análises do comprimento da maior raiz, número de raízes, altura, número de brotos, massa fresca total, após sete meses do início do experimento. Pode-se observar que a pulverização de ANA, na concentração de 200 $\mathrm{mg} . \mathrm{L}^{-1}$, em plântulas de Oncidium baueri resultou, maior enraizamento e desenvolvimento vegetativo, enquanto que a imersão das plântulas não promoveu resultados satisfatórios.

Palavras-chave: ANA, orquídeas, fitorreguladores, enraizamento

\begin{abstract}
The objective of this study was to evaluate roots formation and vegetative development of Oncidium baueri (Orchidaceae) using naftalen acetic acid (NAA) during the acclimatization phase. The experiment was set up at the Agronomy Department - Universidade Estadual de Londrina - Paraná State, between March and October of 2005. Seedlings were obtained from seeds grew up "in vitro", with culture medium (MS). Seedlings were taken out from dishes and washed using flow water, in order to remove the medium. After this, they were transplanted on trail, with sphagnum substrate and were set up on elevated tables at greenhouse ( $50 \%$ of solar radiation). Auxin was used by two ways: fast plants immersion, during 10 seconds $(\mathrm{T} 2, \mathrm{~T} 3, \mathrm{~T} 4)$ and four weekly spraying on beds $(\mathrm{T} 5, \mathrm{~T} 6, \mathrm{~T} 7)$. Treatments with NAA were: $\mathrm{T} 1-0$

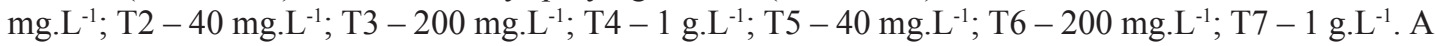
randomized design with seven treatments and three replications was used as statistical model and ten plants composed each plot. Seven months after the trial settle the plants were evaluated by root length; roots number; plant height; sprouts number; and total fresh mass. It was observed that $200 \mathrm{mg} . \mathrm{L}^{-1} \mathrm{NAA}$ spraying on seedlings of Oncidium baueri had better rooting and vegetative development, but seedlings immersion had no satisfactory results.
\end{abstract}

Key words: NAA, orchids, phytoregulators, rooting

1 Bióloga, Esp. Mestranda em Agronomia. E-mail:mauren.uel@bol.com.br.

2 Eng. ${ }^{\circ}$ Agr., Dr., Professor Adjunto do Departamento de Agronomia da UEL, Londrina, PR. E-mail:faria@uel.br.

3 Graduanda de Agronomia da UEL.

4 Bióloga, Esp. Mestranda em Agronomia. E-mail: je_uel@yahoo.com.br.

5 Eng. Agr. Dra. Professora Adjunta do Departamento de Agronomia da UEL.

* Autor para correspondência 


\section{Introdução}

As orquídeas estão entre as plantas ornamentais mais apreciadas e de maior valor comercial. A família Orchidaceae é uma das maiores, constituída por cerca de 700 gêneros e 30.000 espécies (SUTTLEWORTH; HERBERT; GORDON, 1970).

A espécie Oncidium baueri é epífita, crescimento simpodial e pseudobulbos estriados, verde-amarelados, achatados, com 11-13 cm de comprimento e 4-5 cm de largura (GARAY; STACY, 1974).

A semeadura in vitro é uma técnica de produção de mudas em larga escala e de grande interesse para o produtor, mas um percentual de perdas de plantas durante a fase a aclimatização resulta em prejuízo econômico, devido ao alto investimento e emprego de mão-de-obra especializada nessa técnica (GEORGE, 1996).

A etapa de aclimatização é definida como a adaptação climática de um organismo, especialmente uma planta, que é transferida para um novo ambiente ex vitro. Esta fase é muito delicada, deve-se basicamente aos fatores: estresse hídrico, fotossíntese, absorção de nutrientes e fitossanidade (TOMBOLATO; COSTA, 1998). Sendo necessário que a planta habite um substrato que lhe propicie condições para o seu desenvolvimento.

Segundo Díaz-Pérez, Shackel e Sutter (1995), durante o processo da aclimatização ocorre a conversão da condição heterotrófica para autotrófica e em gradual retorno as características naturais da planta.

A perda de mudas durante a aclimatização pode ser muito alta tornando-se um fator limitante no processo de micropropagação (GRATTAPAGLIA; MACHADO, 1990).

As auxinas são fitorreguladores com maior efetividade na promoção de enraizamento, podendo ser utilizada isoladamente ou combinadas no processo de indução de raízes, em concentrações variadas conforme a espécie. As principais auxinas utilizadas são o ácido indol butírico (AIB), o ácido naftaleno acético (ANA), o ácido indol acético (AIA) e o ácido diclorofenóxiacético (2,4-D) (ALVARENGA; CARVALHO, 1983), cuja função está relacionada à divisão celular em cultura de tecido, estimulando a síntese ou desinibindo a ação de enzimas que atuam sobre as microfibrilas da parede celular, resultando em aumento da plasticidade da membrana (KRIKORIAN, 1991; WEAVER, 1976).

O movimento das auxinas é lento e seu transporte através das células do parênquima do floema é polar, ou unidirecional: sempre em direção à base (basípeto) nos caules e folhas, e em direção à extremidade (acrópeto) nas raízes (RAVEN; EVERT; EICHHORN, 1996).

Para Zelená e Fuksová (1991), a presença de auxinas é imprescindível para a indução das raízes, visto que a formação dos primórdios radiculares depende do balanço entre as concentrações de auxinas e de citocininas.

De acordo com Carvalho et al. (1999), trabalhando com plântulas de cafeeiro propagadas in vitro, a imersão de brotações em solução contendo AIB, prejudica o desenvolvimento das plântulas durante a fase de aclimatização.

$\mathrm{Na}$ aclimatização de Dendrobium nobile foi observado que a aplicação de auxinas proporcionou um maior desenvolvimento de raízes e crescimento vegetativo, evidenciando-se que o ácido naftaleno acético foi mais eficiente em relação ao ácido indol acético e o ácido indol butírico (FARIA et al., 2000).

Dentre vários fatores que afetam o enraizamento de estacas, as auxinas desempenham papel importante, sendo os primeiros reguladores químicos a encontrar uma aplicação agronômica bastante difundida (FERRI, 1979).

Segundo Hartmann e Kester (1983), aplicações exógenas de auxina proporcionam maior velocidade, qualidade e uniformidade de enraizamento. $\mathrm{O}$ uso de reguladores de crescimento para induzir o enraizamento difere em sua ação de acordo com a espécie e com o cultivar. Enquanto que algumas espécies enraízam muito melhor com a sua aplicação, outras respondem fracamente ou ainda adversamente. 
Cuquel e Mimani (1994), avaliou o efeito de doses de ácido indol butírico (IBA) e de diferentes tempos de imersão no enraizamento de estacas de Chrysanthemum morifolium cv. white Reagan 606. Esses autores relatam que houve enraizamento em todas as combinações de tratamento e que o tratamento rápido tende a ser mais eficiente quando combinado com as maiores dosagens, enquanto os tratamentos mais demorados com as menores dosagens.

O presente trabalho teve como objetivo avaliar o enraizamento e desenvolvimento vegetativo de plântulas de Oncidium baueri utilizando o ácido naftaleno acético (ANA), durante a fase de aclimatização.

\section{Material e Métodos}

O experimento foi conduzido na Casa de Vegetação, com 50\% de luminosidade, do Departamento de Agronomia, da Universidade Estadual de Londrina (UEL), no período de março à outubro de 2005.

Foram utilizadas plântulas de Oncidium baueri, propagadas in vitro com seis meses de semeadura, com aproximadamente $3 \mathrm{~cm}$ de altura média, quando foram retiradas dos vidros e lavadas em água corrente para a retirada de todo o meio de cultura (MS). Em seguida foram transplantadas em bandejas de isopor, com dez furos na parte inferior, contendo esfagno como substrato.

A cada trinta dias foi realizada uma adubação foliar com a formulação NPK: 6-6-8, na concentração de 1 $\mathrm{ml} . \mathrm{L}^{-1}$. A irrigação foi realizada manualmente duas vezes ao dia no verão, e uma vez ao dia no inverno.

A auxina utilizada foi o ácido naftaleno acético (ANA), nas concentrações 0 mg.L. $\mathrm{L}^{-1}, 40 \mathrm{mg} . \mathrm{L}^{-1}, 200$ mg. $\mathrm{L}^{-1}, 1$ g. $\mathrm{L}^{-1}$. As aplicações da auxina foram realizadas por meio da imersão rápida das plântulas por $10 \mathrm{~s}$, antes do transplantio, e através de pulverizações semanais no substrato das bandejas de $5 \mathrm{~mL}$ nas concentrações com auxina descritas acima durante quatro semanas. O delineamento experimental empregado foi inteiramente casualizado com sete tratamentos e três repetições contendo dez plântulas cada.

A avaliação foi realizada após sete meses do início do experimento, dos seguintes parâmetros: comprimento da maior raiz, número de raízes, altura, número de brotos, massa fresca total.

Os dados obtidos foram submetidos a análise de variância pelo teste de Tukey à 5\%. Para a análise estatística, os dados foram transformados em raiz quadrada para as variáveis números de brotos e números de raízes.

\section{Resultados e Discussão}

Os resultados de comprimento da maior raiz, número de raízes, altura, número de brotos e massa fresca total, são apresentados na Tabela 1 .

Os resultados da análise estatística do comprimento da maior raiz, massa fresca total e altura da plântula indicam que os melhores resultados ocorreram no tratamento 6 , com quatro pulverizações semanais no substrato de ácido naftaleno acético (200mg.L $\mathrm{m}^{-1}$ ) (Tabela 1).

Quanto ao enraizamento de estacas caulinares de azaléia, o uso de concentrações de NAA (ácido naftaleno acético) ou da combinação deste com IBA (ácido indol butírico) já foi testado com resultados satisfatórios (ADAMS; ROBERTS, 1967; NAKAMURA; MATSUI; HARADA, 1978).

Em relação ao número de raízes o tratamento 6 $(11,1)$ apresentou maior número e não diferiu estatisticamente de T3, T4, T5 e T7, sendo que T1 e T2 apresentaram número inferior. A indução de um maior número de raízes propicia uma maior absorção de água e nutrientes, consequentemente promovem um maior desenvolvimento vegetativo. 
Tabela 1. Médias referentes à comprimento da raiz, número de raízes, altura, número de brotos, massa fresca total de plântulas de Oncidium baueri, após sete meses do início do experimento.

\begin{tabular}{|c|c|c|c|c|c|}
\hline $\begin{array}{c}\text { Tratamentos com } \\
\text { (ANA) }\end{array}$ & $\begin{array}{l}\text { Comprimento da } \\
\text { maior raiz }(\mathrm{cm})\end{array}$ & $\begin{array}{l}\text { Número de } \\
\text { raízes (*) }\end{array}$ & Altura (cm) & $\begin{array}{c}\text { Número de } \\
\text { brotos }(*)\end{array}$ & $\begin{array}{c}\text { Massa fresca } \\
\text { total (mg) }\end{array}$ \\
\hline $\begin{array}{l}\text { T1 - } 0 \text { mg. } \mathrm{L}^{-1} \\
\text { Imersão rápida }(10 \mathrm{~s})\end{array}$ & $3,73 \mathrm{c}$ & $7,2 \mathrm{~b}$ & $2,57 \mathrm{~cd}$ & $3,0 \mathrm{c}$ & $0,44 \mathrm{c}$ \\
\hline $\mathrm{T} 2-40 \mathrm{mg} \cdot \mathrm{L}^{-1}$ & $3,76 \mathrm{c}$ & $7,9 \mathrm{~b}$ & $3,37 \mathrm{bc}$ & $3,3 \mathrm{bc}$ & $0,61 \mathrm{abc}$ \\
\hline T3 - $200 \mathrm{mg} \cdot \mathrm{L}^{-1}$ & $5,57 \mathrm{ab}$ & $8,6 \mathrm{ab}$ & $3,05 \mathrm{bcd}$ & $3,7 \mathrm{bc}$ & $0,57 \mathrm{bc}$ \\
\hline $\begin{array}{l}\mathrm{T} 4-1 \mathrm{~g} \cdot \mathrm{L}^{-1} \\
\text { Pulverização semanal } \\
(5 \mathrm{ml})\end{array}$ & $5,0 \mathrm{bc}$ & $10,4 \mathrm{ab}$ & $2,39 \mathrm{~d}$ & $4,4 \mathrm{ab}$ & $0,54 \mathrm{bc}$ \\
\hline $\mathrm{T} 5-40 \mathrm{mg} \cdot \mathrm{L}^{-1}$ & $4,13 b c$ & $11,1 \mathrm{a}$ & $2,56 \mathrm{~d}$ & $4,2 \mathrm{ab}$ & $0,65 \mathrm{ab}$ \\
\hline $\mathrm{T} 6$ - $200 \mathrm{mg} \cdot \mathrm{L}^{-1}$ & $6,96 \mathrm{a}$ & $8,2 \mathrm{a}$ & $4,31 \mathrm{a}$ & $5,3 \mathrm{a}$ & $0,79 \mathrm{a}$ \\
\hline $\mathrm{T} 7-1$ g. $\mathrm{L}^{-1}$ & $4,83 \mathrm{bc}$ & $9,4 \mathrm{ab}$ & $3,38 \mathrm{~b}$ & $4,0 \mathrm{bc}$ & $0,68 \mathrm{ab}$ \\
\hline CV\% & 25,36 & 24,96 & 19,23 & 21,51 & 24,76 \\
\hline
\end{tabular}

*Dados sob transformação raiz quadrada.

**Médias seguidas de mesma letra na coluna não diferem entre si pelo Teste de Tukey a 5\% de significância.

Pereira et al. (1991), em trabalho com goiabeira (Psidium guajava L.) constataram que a aplicação de IBA nas estacas, mostraram precocidade de iniciação radicular e maior número e peso de raízes.

Para a variável número de brotos, os melhores tratamentos foram T4, T5 e T6, com 4 a 5 brotos por plantas.

De acordo com Faria et al. (2000), o ácido naftaleno acético, na concentração de $25 \mathrm{mg} . \mathrm{L}^{-1}$, foi o melhor fitorregulador promotor do enraizamento e crescimento vegetativo de Dendrobium nobile.

\section{Conclusão}

A aplicação do ácido naftaleno acético na concentração de $200 \mathrm{mg}$. $\mathrm{L}^{-1} \mathrm{em}$ quatro pulverizações semanais foi o mais eficiente no enraizamento e desenvolvimento vegetativo de plântulas de Oncidium baueri, durante a etapa de aclimatização.

\section{Referências}

ADAMS, D. B.; ROBERTS, A. N. A morphological time scale for predicting rooting potencial in Rhododendron cuttings. American Society for Horticultural Science, Alexandria, v.91, p.753, dec. 1967.
ALVARENGA, L. R.; CARVALHO, V.D. Uso de substâncias promotoras de enraizamento de estacas frutíferas. Informe Agropecuário, Belo horizonte, v.9, n.101, p.47-55, 1983.

CARVALHO, G. R.; PASQUAL, M.; RESENDE, E.; SCARANTE, M. J.; CARVALHO, G. R. Aclimatização de plântulas de cafeeiro (Coffea arabica) propagadas "in vitro". Ciência Agrotécnica, Lavras, v.23, n.3, p.483-490, 1999.

CUQUEL, F. L.; MIMANI, K. Enraizamento de estacas de crisântemo [Dedranthema morifolium (RAMAT.) TZVELEV] tratadas com ácido indolbutírico veiculado em talco. Scientia Agrícola, Piracicaba, v.51, n.1, 1994.

DIÁZ-PÉREZ, J.; SHACKEL, K. A.; SUTTER, G. G. Acclimatization and subsequent gas exchange, water relations, surviral and growth of microculture apple plantlets after transplanting them in soil. Physiologia Plantarum, Copenhagen, v.9, p.225-232, 1995.

FARIA, A. P.; CAVENAGHI, B.; MÜLLER, C. B.; BENEVUTO, L.; FARIA, R. T. Aplicação dos fitorreguladores enraizadores em mudas de orquídeas em diferentes concentrações. In: MOSTRA ACADÊMICA DE TRABALHOS DE AGRONÔMIA (MATA), 4., 2000, Londrina. Resumo... Londrina: UEL, 2000. p.89.

FERRI, M. G. (Coord.). Fisiologia vegetal. São Paulo: Ed. Universidade de São Paulo, 1979. v.2.

GARAY, L. A.; STACY, J. E. Synopsis of the genus Oncidium. Bradea, Rio de Janeiro, v.1, n.40, p.393-427, 1974.

GEORGE, E. F. Plant propagation by tissue culture. 2 ed. Edington: Exejetics, 1996. Pt.2. 
GRATTAPAGLIA, D.; MACHADO, M. A. Micropropagação. In: TORRES, A. C.; CALDAS, L. S. (Ed.). Técnicas e aplicações da cultura de tecidos de plantas. Brasília: ABCTP/Embrapa, 1990. p.99-170.

HARTMANN, H. T.; KESTER, D. E. Plant propagation: principles and practices. 4 ed. New Jersey: Prentice-Hall, 1983.

KRIKORIAN, A. D. Médios de cultivo: generalidades, composición y preparación. In: ROCA, W. M.; MIROGINSKY, L. A. (Eds.). Cultivo de tejidos em la agricultura: fundamentos y aplicaciones. Cali: CIAT, 1991. p.41-77.

NAKAMURA, M.; MATSUI, S.; HARADA, H. Effect of some methods and auxin treatments on the rooting of stem cuttings taken from mature trees. Journal of the Japonese Society for Horticultural Sciense, Tokyo, v.47, n.2, p.227236, 1978.
PEREIRA, F. M.; PETRECHEN, E. H.; BENINCASA, M. M. P.; BANZATTO, D. A. Efeito do ácido indolbutírico no enraizamento de estacas herbáceas de goiabeira (Psidium guajava L.) das cultivares "Rica" e "Paluma", em câmara de nebulização. Científica: revista de agronomia, São Paulo, v.19, n.2, p.199-206, 1991.

RAVEN, P. H.; EVERT, R. F.; EICHHORN, S. E. Biologia vegetal. 5.ed. Rio de Janeiro: Guanabara Koogan, 1996.

SUTTLEWORTH, F. S.; HERBERT, S. Z.; GORDON, W. D. Orchids. São Francisco: Western Publishing Company, 1970.

TOMBOlato, A. F. C.; COSTA, A. M. M. Micropropagação de plantas ornamentais. Boletim Técnico, Campinas, v.174, p.1-72, 1998.

WEAVER, R. J. Reguladores del crescimento de las plantas en la agricultura. México: Trillas, 1976.

ZELENÁ, E.; FUKSOVÁ, K. The effect of índole-3acetylaspartic acid on adventitious root formation on bean cuttings. Plant Growth Regulation, Dordresh, v.10, p.73$78,1991$. 
